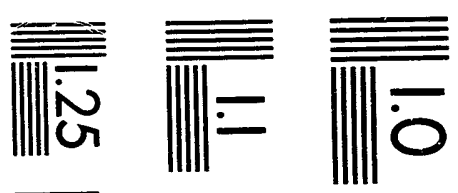

$$
\begin{aligned}
& \overline{\underline{\underline{\underline{\underline{1}}}}}
\end{aligned}
$$

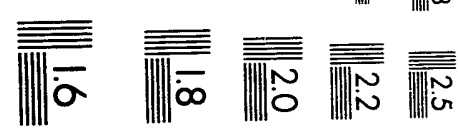



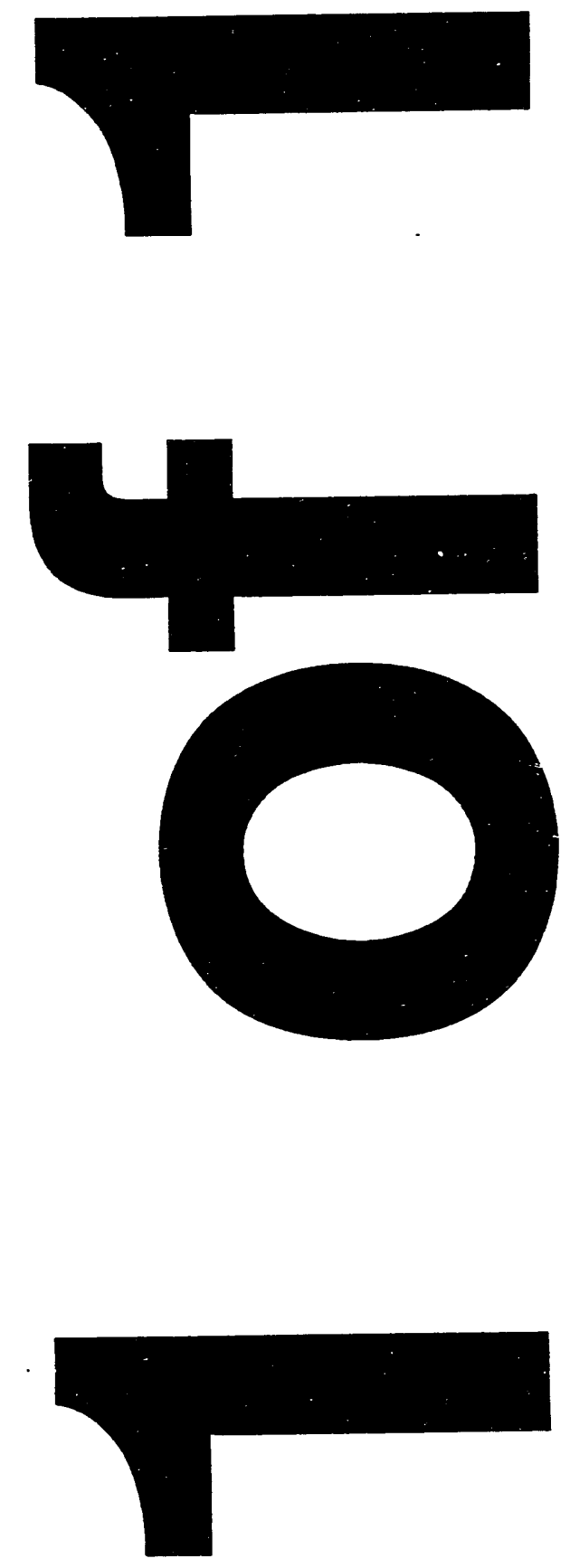
Effects of Ionizing Radiation

on Modern Ion Exchange Materials

S. Fredric Marsh

K. K. S. Pillay 


\section{CONTENTS}

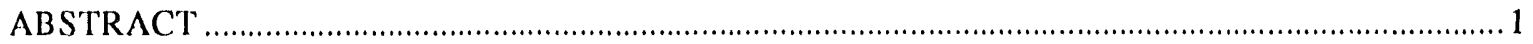

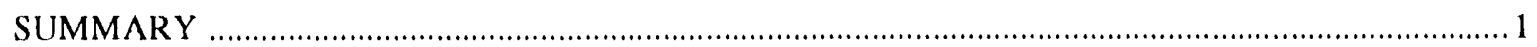

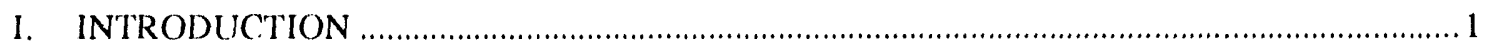

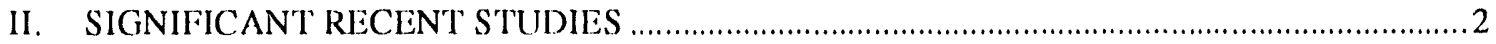

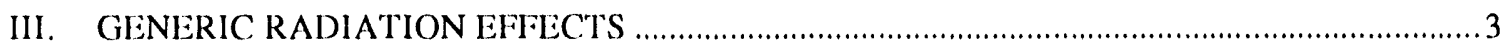

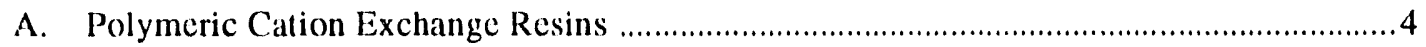

B. Polycondensation-Type Cation Exchange Resins ........................................................ 4

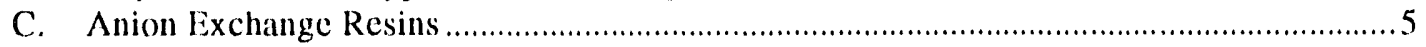

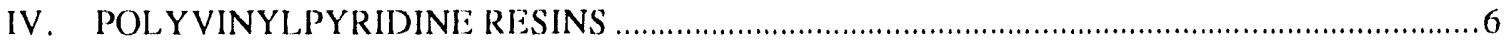

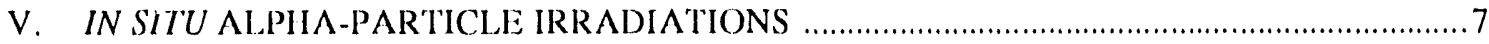

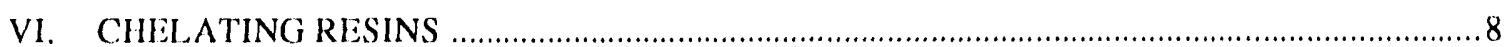

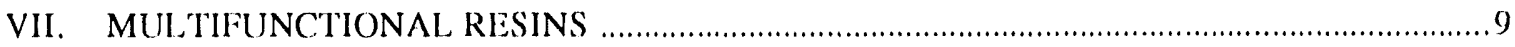

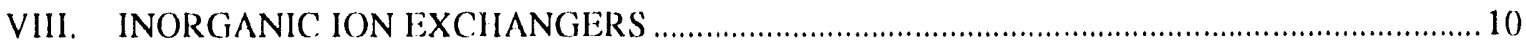

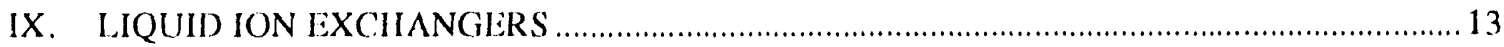

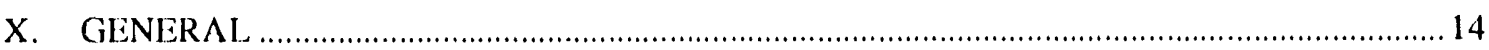

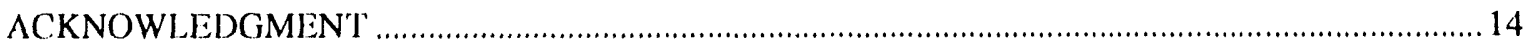

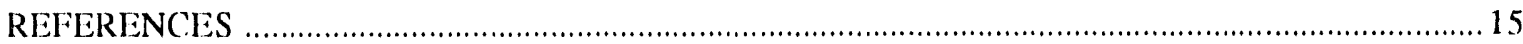




\title{
EFFECTS OF IONIZING RADIATION ON MODERN ION EXCHANGE MATERIALS
}

\author{
by
}

\author{
S. Fredric Marsh and K. K. S. Pillay
}

\begin{abstract}
We review published studies of the effects of ionizing radiation on ion exchange materials, emphasizing those published in recent years. A brief overview is followed by a more detailed examination of recent developments. Our review includes styrene/divinylhenzene copolymers with cation-exchange or anion-exchange functional groups, polyvinylpyridine anion exchangers, chelating resins, multifunctional resins, and inorganic exchangers. In general, strong-acid cation exchange resins are more resistant to radiation than are strong-hase anion exchange resins, and polyvinylpyridine resins are more resistant than polystyrene resins. Cross-linkage, salt form, moisture content, and the surrounding medium all affect the radiation stability of a specific exchanger. Inorganic exchangers usually, but not always, exhibit high radiation resistance. Liquid ion exchangers, which have been used so extensively in nuclear processing applications, also are included.
\end{abstract}

\section{SUMMARY}

We have updated earlier published reviews of the effects of ionizing radiation on ion exchangers, expanding our coverage to reflect the growing importance of inorganic exchangers, chelating resins, multifunctional resins, and liquid ion exchangers. In addition to reviewing the gencral effects of radiation, we have highlighted studies in which specific anion exchangers were subjected to high levels of in situ alpha particles. Although some investigators have tried to systematically study the effects of radiation on several new ion exchangers and confirm previous findings, appreciable gaps remain in our understanding of these radiation-damage mechanisms.

Radiation stability is a particularly important consideration when selecting materials for processing nuclear waste. We therefore cite a just-completed evaluation of 60 candidate absorbers for partitioning Ifanford High-level Tank waste. The most promising absorbers identified in that study should be evaluated for their radiation stabilities, when such information is not already availabie.

\section{INTRODUCTION}

Ion exchangers have always had a major role in pollution abatement in nature. Natural ion exchangers, such as soils, sand, clays, rocks, and decayed plant materials help protect aquifers by removing a variety of surface contaminants. The advent of synthetic ion exchangers just before the discovery of nuclear fission allowed a synergism between these two technologies that contributed to significant advances in both fields. Consequently, the nuclear industry has become a major user of ion exchange technology. 
Major users of ion exchangers within the nuclear industry are the commercial nuclear power plants and the producers of fissile and fertile materials for civilian and defense applications. In particular, modern organic ion exchange resins are extensively used to purify the aqueous coolant systems of nuclear power plants. Numerous ionexchanger systems and technologies are used worldwide to maintain the aqueous coolant systems of approximately 415 land-based nuclear power plants and an equal number of nuclear plants used for marine propulsion. The stringent requirements of reactor coolant systems make most nuclear facilitics large-scale users of organic ion exchange resins. Between 10,000 and 25,000) liters of ion exchangers are used annually for coolant maintenance in a typical nuclear facility. ${ }^{1}$ These facilities also use large guantities of organic and inorganic ion exchangers for waste management and pollution abatement.

A unique pollution abatement application of ion exchangers currently receiving much altention is in the isolation of hazardous components of high-level nuclear wastes from fuel reprocessing. Decades of reprocessing irradiated fuel from production reactors at nuclear defense sites has left large quantities of highly radioactive wastes in underground storage tanks. The US Department of Energy is committed to recovering and concentrating the hazardous components from these wastes 10 isolate them from the biosphere. Ion exchangers that can function in an intense radiation environment are highly desirable for this application.

Ion exchangers used in the nuclear industry are subjected to ionizing radiation fields of varying intensitics. Because extended exposure to ionizing radiation is known (o) damage ion exchangers, ${ }^{2,3}$ there is great interest in understanding the radiolytic danage mechanisms and in developing materials that offer greater resistance to such hostile environments. Alfempts to develop a detailed understanding of the damage mechanisms have been only partially suceessful. Nevertheless, properties of radiation-resistant substrates have been identified and used to make improved ion exchangers for the nuclear industry. Such changes in the molecular design of organic resins have improved their radiation resistance, which in turn has resulted in superior materials for specialized applications.

During the past six decades, many hundreds of ion exchange materials have been synthesized and tested. lew, however, have achieved industrial importance. Because the nuclear industry relies heavily on synthetic organic ion exchangers, this is the type most extensively studied for radiation effects. Ilowever, improved new ion exchangers of other lypes are also needed for applications requiring intense radiation exposures and corrosive chemical environments. In recognition of this need, new materials are continually being examined for a variety of nuclear process environments.

Ion exchange materiats used in nuclear material processing are not only subjected to ionizing radiation, they often encounter a hostile chemical environment as well. This combination of aggressive conditions can degrade many ion exchange materials. Because the behavior of ion exchangers subjected to ionizing radiation in typical processing media greatly interests chemists, it has been the subject of many published studies. Three major surveys have reviewed this literature. ${ }^{2,3,4} \wedge$ concise tabulation of the key fealures of these studies is presented in a companion publication to one of these surveys. ${ }^{5}$

The objective of our review is to examine this expanding knowledge base and to highlight new developments relevant (o) radiation effects on ion exchangers. This report is primarily organized by generic types of ion exchangers. Becatuse few in situ irradiation experiments have heen published, we devote a separate section to sone unique in situ experiments and the ir results.

\section{SIGNIFICANT RECENT STUDIES}

To localte significant new information, we examined experimental studies and literalure reviews published since the last comprehensive survey, ${ }^{4}$ which extended through 1984. Several groups of researchers from the former Soviet Union, the (aech Republic, Egypt, and Indiat reported the effects of radiation on ion exchange resins." 13 Because these studies only confirm previous investigations, we chose not to devote space to them in this review. 
Recovery operations at the Three Mile lsland-II reactor, however, produced some noteworthy studies. ${ }^{14,15}$ Those investigations were made to determine the maximum permissible loading of the resins. The research was necessarily limiled to the polymeric strong-acid calion exchange resins and the strong-base, quaternary ammonium-lype anion exchange resins in use at 'I'MI-2. The investigators measured resin-related gas generation, physical damage, increased corrosion of waste containers, and changes in resin pll and flow rate.

An extension of these TMI-2 studies by McConnel et al. ${ }^{16}$ was one of the few published in situ irradiation studies. The Epicor-Il prefilters, which consist of a layered mixture of inorganic and organic cation exchangers, received approximately $1 \mathrm{MGya}$ of cumulative dose from mixed fission products during nine years of TMI-2 cleanup operations. The effects of this in situ exposure were not significantly different from those of exposing similar resin to comparable doses of external radiation.

Other publicalions since 1984 established the superior radiation resistance of a new macroporous polyvinylpyridine anion exchange resin, Reillex ${ }^{\mathrm{TM}} \mathrm{IPQ}{ }^{17}$ The effects of in situ alpha particles were measured on six strong-base anion exchange resins, which included Reillex ${ }^{T M}$ HPQ. ${ }^{18}$ These studies are discussed in later sections.

A novel proposal to use well-characterized ion exchangers 10 measure very high dose rates, where conventional radiation dosimetry is not feasible, seems worthy of further examination. ${ }^{8}$ Finally, a discussion of radiation stability ${ }^{19}$ was included in a review of ion exchange technology in the nuclear fucl cycle published by the International Alomic linergy $\Lambda$ gency.

\section{GENIEIC RADIATION EFFECTS}

Ionizing radiation doses in the range of $10^{5}$ (iy signilicantly alter the properties of most synthetic organic ion exchangers. High absorbed doses affect exchange capacily, selectivity, and exchange kinetics. Other physical and chemical characteristics also change. In general, anion exchangers suffer more radiation damage than do cation exchangers. Radiolytic effects on ion exchangers depend on the nature of the resin itself: its chemical composition, ionic form, moisture conterl, swelling characteristics, and the extent of cross-linkage in the macromolecular structure. Radiolytic changes are also affected by the type of radiation and the resin environment during the irradiation.

Ionizing radiation acts on synthetic organic ion exchangers in two ways. First, direct radiolytic effects lead to the scission of functional groups, the formation of free radicals, and hydrolytic reactions of the species formed. Second, interactions oceur between the ion exchanger and highly reactive radiolysis products in the surrounding medium.

Investigators have proposed mechanisms for the observed radiolytic effects on synthetic organic resins, based on knowledge of the radiolysis of synthetic polymers in water. ${ }^{2.2123}$ IIowever, our present knowledge is inadequate to evaluate the reaction-rate constants of the controlling radiolytic processes or to develop useful models for radiolysis in ion exchangers. Many radiation studies have been confirmed by investigations of similar types of resins of different origin; nevertheless, disagreements exist in several areas and some conclusions remain debatable.

Research with in situ radiation sources is especially desirable, but such experiments are especially challenging because all post-irradiation measurements must be done on radioactive resin. For this reason, nearly all published data are from resins exposed (o) external sources, such as $x$-ray machines, ${ }^{61}$ Co, electron aceclerators, and in a few cases rescach reactors. $A$ separate section of this report discusses experiments in which modern ion exchange resins have been subjected to in situ alpha parlicles; such studies are particularly relevant because they closely simulate the actual processing environment.

"Gray is the SI unit of absorbed dose. 1 Gy $=1 \mathrm{~J} / \mathrm{kg}=100 \mathrm{rad}$. 
Properties of ion exchange resins and irradiation effects that can be quantified for comparison purposes include (a) radiation chemical yicld or G-value, (b) swelling/shrinkage of the resin matrix, (c) weight change, (d) solubility, (c) gas evolution, (1) water content and (g) formation of ionic species. These data and their original references are compiled in the two reviews cited earlicr. ${ }^{2,4}$

\section{A. Polymeric Cation Exchange Resins}

The commercial importance of polymeric cation exchangers, such as the styrene-divinylbenzene-sulfonic acid resins, has focused experimental studies on this type. Studies have demonstrated that the radiation chemical stability of polymeric cation exchange resins depends on the degree of eross-linkage of their macromolecular structure. (The cross-linkage of polymeric resins is defined as the pereent divinylbenzene used in the resin preparalion.)

Early work by Wedermeyer ${ }^{24}$ and Cathers ${ }^{25}$ and later contributions by Semushin ${ }^{26}$ and Kiseleva ${ }^{27}$ are typical of studies that demonstrate the relationship between resin cross-linkage and radiation stability. Many other investigators also have concluded that higher cross-linkage increases the radiation stability of synthetic organic ion exchange resins. ${ }^{28-37}$ Jowever, a few exceptions to this generalization, such as those reported by Tulupov, ${ }^{29}$ do exist.

$\Lambda$ common measure of ion exchanger stability is the change in tolal exchange capacity as a function of radiation dose. Many commercial polymeric cation exchangers have been evaluated in this way. ${ }^{5}$ llowever, very few experimental studies of radiation-induced chemical effects yield quantitative data that can be extended to an entire class of synthetic resins.

Dilfering results from various experimental studies may partly reflect diflerences in resin constituents. Such differences can stem from common impuritics in the polymerization reactants. This was demonstrated by Wiley and coworkers ${ }^{34,38,39}$ in their systematic comparison of the constiluents of commercial divinylbenzene, and of the radiation stabilitics of various resins wilh known constituents.

\section{B. Polycondensation-Type Cation Exchange Resins}

Cation exchange resins of the polycondensation type are more resistant to radiation damage than are polymeric resins, although their chemical, mechanical, a do thermal propertics are significantly worse. This generalization is confirmed by experimental studies of many organic resins. ${ }^{2,25,40}$ 48 Changes in total exchange capacily, swelling, weight loss, gas evolution, and the appearance of new functional groups are common to both types of organic cation exchange resins; however, a comparable dose causes less change in polyeondensation-lype resins.

Among strong-acid type cation exchange resins containing carbon-sulfur bonds, chemically unstable phenolsulfonic acid-formaldehyde resin is more stable (o) ionizing radiation in many aqueous solutions than are the more chemically stable slyrene-divinylbenzene-sulfonic acid resins. Studies show that weak-acid carboxylic acid resins containing carbon-carbon honds are more resistant to radiation than are strong-acid resins containing catbonsulfur, carbon-phosphorus, or carbon-oxygen bonds. $42,43,45$

A polycondensation-type resin hased on salicylic acid and furfural is reported to be more resistant lo radiation than several condensation-type sulfonic acid derivatives. ${ }^{42}$ Its exchange capacity and other chanacteristics are unchanged after radiation doses of 2 MCy. Shigematsu and (Oshio ${ }^{43}$ have confirmed this gencralization about the relative radiation stability of weak-acid carboxylic and phenolic-base cation exchangers. 


\section{Anion Exchange Resins}

Polymeric resins with quaternary ammonium groups are the most important anion exchangers in the nuclear industry. These resins have been the subject of many studies during the past three decades. $2,4,24,32,43,4968$ IIowever, very few of these experimental studies provide useful quantitative data.

Radiation-indised chemical changes in these resins are characterized by datkening of the resin, evolution of odorous free amines, gas evolution, loss of exchange capacily, and degradation of the resin matrix. The resistance of anion exchange resins (o radiation generally varies litlle with the basicity of the resin. Those having aromatic systems with conjugated bonds in the functional groups are more radiation resistant than other types of synthetic organic anion exchangers.

Most polymeric anion exchangers are based on styrene-divinylbenzene copolymers. Although this structure is highly resistant to radiation damage, anion exchangers that contain quaternary, lertiary, secondary, or primary amino groups do begin to show significant attrition at doses of about ().1 M(iy. By contrast, calion exchangers, based on a slyrenc-divinylbenzene copolymer, generally suffer litlle damage from a comparable dose. The altrition of anion exchangers is usually greater in the presence of water or aqueous electrolytes than in otherwise similar irradiations of dry resins.

Dala for radiation effects on anion exchangers indicate that radiation-induced chemical changes in strong-base monofunctional anion exchangers follow a rather complex mechanison. There may be (wo types of exchange groups, which differ in their relative stability toward radiation-indueed chemical changes. ${ }^{2,56,57}$ These groups are believed to he allached to the aromatic ring in the ortho or para positions, with the ortho groups being less stable than the para substituents. ${ }^{56}$

Experiments suggest that quaternary-iunmonium type resins decompose primatrily through deamination, which breaks the carbon-nitrogen bonds that connect the trimethylamine groups to the benzyl radicals. ${ }^{53,54,57}$ Egarov and Novikov state in their classic work that anion exchange resins of the quaternary anmonium type lose exchange capacily primarily by decomposition of the functional groups. ${ }^{2}$ These authors suggest that the decomposition depends on the nature of the functional groups and the ionic form.

Anion exchangers with quaternatry anmonium base groups, when irradiated, steadily lose their strong-base exchange capacity. However, some of the strong-base groups convert to weakly basic amino groups, which temporarily increase the total exchange capacity of the resin. ${ }^{3.57}$ Irradiation of anion exchangers also reportedly forms oxidation-induced carboxyphenolic and hydroxy groups. As with cation exchangers, anion exchange resins with high cross-linkage experience less radiation danage. $2,24,53$

Also, as with catton exchangers, the salt forms of anion exchangers are reported to be more radiation resistant. Although exceptions exist, the nitrate, chloride, chlorate, and sulfate forms of anion exchangers generally are more

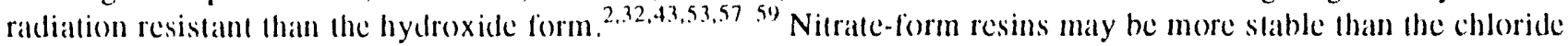
form because nitrate ions can scalvenge hydrated electrons, whereas chloride radicals are strongly oxidizing.

A representative study on the loss of capacity of anion exchange resins ${ }^{49}$ indicates that the ionic form and the environment of the resin during irradiation both influence radiation-induced chemical changes.

Several investigators characterized the radiolytic decomposition products of anion exchange resins. ${ }^{49,54,57-62}$ They measured yiclds of fertiary, secondary, and primary aliphatic amines and ammonia. Irradiation of anion exchangers having guaternary ammonium groups produces soluble amines and ammonia, with trimethylamine as the major product; however, the yields depend in a rather complex manner on the moisture content of the resin.

The radiation chemistry of polycondensation type resins has been less rigorously explored, and many features of their radiolysis remain unexplained. 


\section{POLYVINYLPYRIDINE RESINS}

Previous radiation stability studies $s^{4,22}$ have identified anion exchange resins with a pyridine functional group in a vinylpyridine-divinylbenzene copolymer as more resistant to radiation than polystyrene resins. Moreover, these polyvinylpyridine resins have greater resistance to altack by nitric acid, an important consideration in many nuclear industry processes.

Most conventional strong-base anion exchange resins are copolymers of styrene and divinylbenzene. Because styrene polymers can react violently with nitric acid under certain conditions, such hazardous conditions must be stringently avoided. Potential safely hazards of using ion exchange resins in nitric acid systems have been addressed by Calmon; ${ }^{(1)}$ some actual failures were summarized by Miles. ${ }^{70}$

Vinylpyridine polymers should be more resistant to nitric acid than is polystyrene. Polystyrene is susceptible to clectrophilic aromatic substitution, whereas the electronegativity of nitrogen in the pyridine ring makes polyvinylpyridine highly resistant to such substitution.

More than 30 years ago Permutit ${ }^{\mathrm{TM}}$ SK, a gel-type polyvinylpyridine anion exchange resin, was reported to offer superior sorption and desorption kinctics ${ }^{71}$ and capacity ${ }^{72}$ for plutonium, as well as greally increased stability against chemical attack ${ }^{73}$ and radiolytic degradation. ${ }^{3}$ Permutit ${ }^{T M}$ SK (no longer manulactured) is a copolymer of 2-methyl-5-vinylpyridine and divinylhenzene.

More recently, Zainutdinov et al. ${ }^{74}$ studied the gamma-radiation resistance of anion exchange resins based on epichlorohydrin and 2-vinylpyridine or 2-melhyl-5-vinylpyridine, both dry and immersed in water. Resins irradiated to 2.6 MGy were compared with their unirradiated counterparts. The capacities, wet volumes, weights, and mechanical strengths of the irradiated resins decreased by only a few percent in all cases, compared with a $30 \%$ swelling and $25 \%$ loss of strength for $\mathrm{AN}-31$, an industrial anion exchange resin without pyridine functionality.

Several years ago, Reilly lndustries of Indianapolis, a manulacturer of vinylpyridine polymers, began producing a macroporous polyvinylpyridine anion exchange resin. This new resin, Reillex ${ }^{\prime M}$ HIP(), is a copolymer of 1 -methyl-4-vinylpyridine and divinylbenzene. The sorption kinetics of Reillex ${ }^{T M}$ HPQ were reported to be comparable or superior $(0)$ the hest commercial anion exchange resin previously identilied. ${ }^{75}$ the chemical resistance of Reillex ${ }^{T M}$ IIPQ was evaluated hy subjecting this resin to boiling nitric acid under reflux for three hours. ${ }^{75} \mathrm{Al}$ though a small quantity of $\mathrm{NO}$, fumes was ohserved, the dry weight of the resin was essentially unchanged by this severe treatment. The wet resin volume, however, increased by about $10 \%$.

The swollen resin provided faster sorption kinetics and a capacity increase of nearly $20 \%$, which indicated that some of the divinylbenzene cross-linking groups had cleaved. ${ }^{75}$ Such cleavage would he expected to relax the resin structure and allow the beads to expand, in accord with the observed swelling. The more open structure of the expanded beads should make the interior anion exchange sites more acessible, which would account for the increased capacity and improved sorption kinetics.

The effects of gamma radiation on Reillex ${ }^{T M} H P Q$ were compared with the effects on four conventional strongbase polystyrene resins, ${ }^{17}$ including gel-type Dowex ${ }^{T M} 1 \times 4$ and three macroporous resins: Dow ${ }^{T M}$ MSA-1,

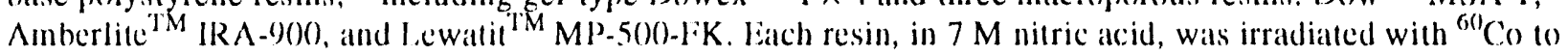
seven levels of gamma radiation ranging from 1 to 10 MCiy. All irradiated resins wese measured for changes in dry weight, volume in $7 \mathrm{M}$ nitric acid, volume in water, strong-base and weak-base chloride exchange capacily, Pu(IV) exchange capacity, and thermal stability. of the resins tested, Reillex TM IIPQ was found to be the most stable against damage by gauma radiation, whereas l.ewatit ${ }^{T M}$ MP-5(K)-liK was the least stable.

The resistance of Reillex TM IIPQ to in situ alpha particles also was compared to that of five other strong-base anion exchange resins. ${ }^{\text {IR }}$ This study included the five resins used in the cited gammatirradiation study plus one

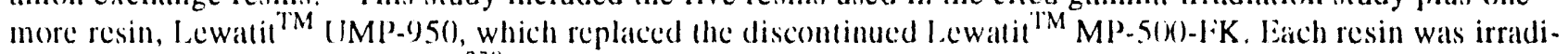
atced in $7 \mathrm{M}$ nitric acid by sorbed ${ }^{238} \mathrm{P}_{1} \mathrm{l}(\mathrm{)}) \mathrm{doses}$ of approximately $5,8,11$, and $14 \mathrm{M}$ (iy. The resins were measured 
for all properties cited in the preceding paragraph, except thermal stability. As in the gatmma-irradiation study, Reillex ${ }^{T M}$ HPQ provided the greatest stability against alpha particles, whereas Iewatit ${ }^{T M}$ MP-50)-ISK was the least stable of the resins tested.

\section{IN SITL AI,PHA-PAR'TICLLE IRRADIATIONS}

Mest investigations of the effects of radiation on ion exchange resins use an external source of ganma radiation, generally ${ }^{61)}$ (o). Lexperiments that involve in situ alphat-particle irradiations are relatively rate. An extensive compilation by (Bangwer et al. ${ }^{3}$ lists hundreds of irmdiations of ion exchange resins by a variely of external sources including gamma rays, $x$-rays, alecelerated electrons, and spent reactor fucl, of the cited studies, however, none involving anion exchange resin and only two involving calton exchange resin used in situ alpha particles. The investigators' preference for external soures is understandable. Because external sourees leave no residual radioactivity in the resin, subsequent measurements of the resin can be made using benchtop procedures, rather than requiring the complication and inconvenience of glove-hox operations.

Despite the added difficulty of working with in situ atpha particles, such studies are necessary (o) realistically simulate the radiation environment of ion exchangers in actinide separation processes.

Kazanjian and Horrell ${ }^{76}$ compared the effects of gamma rays and alpha particles on Dowex ${ }^{\text {TM }} 50 \mathrm{~W} \times 4$ cation exchange resin. They concluded that the ion exchange sites were similarly affected, but that alpha particles citused greater damage to the polymer matrix.

Spechl cl all. ${ }^{77}$ exposed Dowex ${ }^{\mathrm{TM}} 50 \mathrm{~W} \times 8$ cantion exchange resin to dose raltes of $0.025,0.10,0.185 \mathrm{M}$ (iy per hour of in sittl alpha particles from sorbed ${ }^{242}(\mathrm{~m}$, and also lo gamma dose rattes of 0.10 and 0.185 MCiy per hour from an operating nuclear reactor. The strong-acid capacity of the resin was decreased about $50 \%$ by a 20 -MGy Jose of either alpha particles or gamma radiation. This decrease was attributed to sulfonic acid functional groups being split oft. For a given total dose of either alpha particles or gamma rays, the capacity loss was highest at the lower dose ralles.

Paramonova and coworkers ${ }^{78}$ evaluated the effects of alpha particles from sorbed plutonium on $A \mathrm{~V}-23 \mathrm{M}$ anion exchange resin, a copolymer of 2 -methyl-5-vinylpyridine cross-linked with $7 \%$ wivinylbenzene. This resin relained $91 \%$ of its initial capacity after alpha-particle exposures $2.57 \mathrm{MC}$ (iy. Although resin weight loss was not reported, a dose of $3.42 \mathrm{Me}$ iy decreased the resin cross-linkage $10.3 .3 \%$.

Alrens ${ }^{79}$ measured the effects of alpha particles on Dowex ${ }^{7 \mathrm{M}} 1 \times 4$ in nitric acid, and compared his results with those of another investigator who had previously studied the effects of gamma radiation on that resin. The capacity loss ciased by $1.00 \mathrm{M}$ (iy of alpha particles was less than half that caused by a comparable gatmma dose.

The effects of alphat and gamma radiation were compared in a dissertation by Ahmed. ${ }^{80}$ Ahmed found the capacily loss for sulfate-form anion exchange resin was 2 to 2.5 times grealer from gamma radiation than from a comparable dose of alpha particles.

Marsh ${ }^{81}$ compared the effects of in situ alpha particles 10 those of exlernal gammat radiation on five strong-base anion exchange resins: Reillex ${ }^{T M} I I P Q$, a polyvinylpyridine resin, and four conventionai strong-batse polystyrene resins, which included gel-lype Dowex ${ }^{\text {TM }} 1 \times 4$ and three macroporous resins (Dow ${ }^{\text {TM }}$ MS $\Lambda-1$, Amberlite ${ }^{\text {TM }}$ IR $A$ $9(0)$, and Lewatit $\left.{ }^{\mathrm{TM}} \mathrm{MP}-5()()-\mathrm{FK}\right)$. Bach resin, in $7 \mathrm{M}$ nitric acid, was irradiated with ${ }^{61} \mathrm{Co}$ (o) seven levels of gamma radiation ranging from $11010 \mathrm{M}$ (iy, and also (o) alpha doses of $5,8,11$, and $14 \mathrm{MC}$ (iy from sorbed ${ }^{238} \mathrm{Pu}$. (The alphat-iradiation study ${ }^{18}$ included one additional resin, lewatio ${ }^{T M}$ UMP-95(), which replaced discontinued lewatit ${ }^{\mathrm{TM}} \mathrm{MP}-50()-\mathrm{FK}$.) 
All irradiated resins were measured for changes in dry weight, volume in $7 \mathrm{M}$ nitric acid, volume in water, strong-base and weak-base chloride exchange capacities, Pu(IV) exchange capacity, and thermal stability. Of the lested resins, Reillex ${ }^{T M}$ IIPQ was the most slable to gamma radiation and alpha particles, whereas Lewatio ${ }^{1 M}$ MP50)-FK was the least stable.

All of these resins survived alpha particles better than gamma radiation. Weight losses were substantially higher from gamma radiation than trom an equivalent exposure to alpha particles. $\wedge$ remarkahle $97 \%$ of the initial weight of Reillex ${ }^{T M}$ IIPQ resin survived even the highest alphat dose of $14.3 \mathrm{MGy}$. Plutonium(IV)-capacities of these same resins from $7 \mathrm{M}$ nitric acid during a 15-miaule dynamic contact confirmed that all resins were significantly less danaged by alpha particles than hy a comparable dose of giunma radiation.

Resin damage from alpha particles was gencrally less than half that caused by an equivalent dose of gamma rays. Much of the resin danage was altributed to secondary reactions hetween the resin and radiolysis products of nitric acid. This is consistent with differences in experimental conditions, wherehy a larger quantity of nitric acid was exposed to radiation in the ganma-irradiation study. ${ }^{18}$

\section{CHELATING; RESINS}

Myasocdova and Savvin ${ }^{82}$ presented al comprehensive review (with 247 references) of chelating sorbents and their uses in analytical chemistry. Millat el at. ${ }^{\times 3}$ reviewed approximately 50 commercial chelating resins and stated, ". . only a lew are in fact eommercially viable. and none even approaches the original eriterion (of being selec(ive)." Sengupta and Zho ${ }^{8-4}$ have suggested applications for several chelating polymers with nitrogen donor atoms. Green and llancock ${ }^{8.5}$ studied pyridyl-imedazole and pyridyl-melhyl-imidazole resins. leccles and Greenwood ${ }^{86}$ recently reviewed past and future applications of chelate ion exchangers. Although many chelating exchangers appear suitable for removing radionuclides from waste streams, relatively few have been studied for radiation stability.

An extensive review of the action of ionizing radiation on ion exchangers by Egorov and Novikov, ${ }^{2}$ published nearly 30 years ago, devoled several pages to carboxylic cation exchangers. These authors reported that this type of exchanger is extensively damaged by doses of less than $0.1 \mathrm{M}$ (iy, and that most carboxylic resins cannot be used at doses above 1 Meiy. They concluded (1) higher cross-linkage increases the radiation stability, (2) hydrogen-form resins irradiated dry or in water-swollen form exhibit different radiation stabilities, (3) resins irradialted in their salt forms ate much more susceptible o radiation damage, and (4) phenol-formaldehyde resins, copolymers of acrylic acid, and styrene-1)VB copolymers are more resistant to radiation than those based on methacrylic acid.

More recently, Murty ${ }^{87}$ measured the effects of gamma radiation on carboxylic acid exchangers Zeecarb-226, IR( -50 , and Indion-236. These resins were irradiatled in the hydrogen, ammonium, and sodium forms; either airdried, or in aqueous slurries of demineralized water or of 1:1 ethanol-water mixtures. After 1.2 MGy, at a dose rate of 30) (iy per minute, no major differences among the three resins were observed. However, the resin form and the irradiation medium both alfece the loss of exchange capacily. For dry irradiations, hydrogen-form resins are generally more stable than sodium-form resins, which in turn are more stable that ammonium-form resins. In aqueous solutions, the ridiation damige to hydrogen-form resin is similar to that of a dry irradiation (hased on very limiled data); however, the damage to sodium- and ammonium-form resins is increased. The damage to sodiumand ammonium-form resins in an ethanol-water mixture is less than that incerred in water alone.

Pfrepper et at. ${ }^{8 x}$ studied the resistance of Wof MC 50 Chelon exchanger 600.1102 MGy of gamma radiation. When this resin, which has aminoacetic acid and iminodiacetic acid functional groups, was air-dried or immersed in water or I $\mathrm{M}$ nitric acid during the irradiations, the main reaction was decarboxylation, with a G-value of 13. Irradiations in nitric acid solutions of $7 \mathrm{M}$ or higher concentration resulted in rapid oxidative breakdown of the functional groups, in addition to radiation-induced decarboxylation. 
Jigorov and Novikov? reviewed lle stalls of phosphated calton exchangers of Soviel manufacture in the mid196()s. Leceron-beam iradiations of Rli resin (with a phosphate functional group) to 28 M(iy, in waller and in alyucous clectrolyles, cilused increased swelling but litlle change in capacily. Irradiation of Kl:-1 (another phosphate calion exchanger) 10 4.5 M( iy in water, lactic acid, and acetic acid caused litlle change in swelling or capacily. Those reviewers concluded, from limiled experimental data, that resins containing phosphate functional groups were the most radiallon-resistant resins known at that time, and could be used al doses grealter than 10 Me iy.

(iribanova ed al. ${ }^{8 x}$ evaluated the ratiation, chemical, and mechanical stability of porous organophosphorus exchangers irradiated by "'(') in air, waller, and $2 \mathrm{M}$ nitric acid. The stathility of the porous phosplonic acid exchangers was considerably higher han thal af nonporous exchangers. lon resins polymerized wilh varying rallos of ist)-octanc and divinylhenzenc, the radialion resistance increased with the degree of cross-linkage. Resins

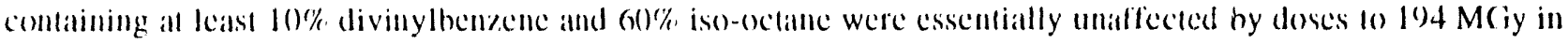
ally of the threce irradiallion media.

'lulopovel all. ${ }^{\text {g) }}$ symhesized a calion exchanger based on the his-2,2'-chlorocthyl ester of vinylphosphonic acid and divinylbenzene. 'The ester groups were saponified in one valtiation of their study to convert the atrylphosphonic acid groups lo alkylphosphonic aced gromps. lexposures in waller lo doses of 1, 2, and 3 Meiy, in waller, resulted in capacity losses of $3.4,4.3$, and $5.7 \%$, respeclively, for the arylphosphonic acid resin; capacity losses were 8.5 , 15.0, alnd $16.3 \%$, respectively, for the alkylphosphonic acid resin. The chemical stabilities of these lwo resins in $3 \mathrm{M}$ (r) $10 \mathrm{M}$ nilric acid were comparable.

Nikelatev and coworkers ${ }^{90)}$ studied the effect of gamma radiation on a series of diallyl and triallyl esters of phosphonic acid. These esters were diallyl phosphate, triallyl phosphate, triallyl medhylphosphomate, diallyl butylphosphonate, diallyl isopentylphosphonate, and diallyl allylphosphonale. batch resin, sealed in a glass fube

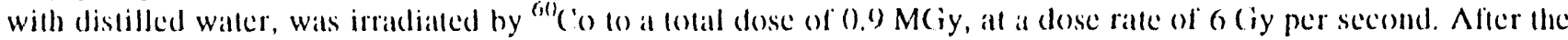
irraliations, the experimenters measured changes in exchange capacity for sodium and uranyl ion, and resin swelling in water and ethanol. All resins except the diallyl phosphate gained capacity for sodium, whereas all resins lost capacily for (J(VI). Resin swelling decreased in water and in ehathol. The decreased swelling and decreased capacity for the large uranyl ion were hoth allributed to a radiation-induced increase in cross-linkage of all resins. Moreover, these investigators proposed that the sorption mechanism was changed as a result of irradiation.

\section{MULITIHUNC'IIONAI, RESINS}

Sovied rescarchers have prepared multifunctional anion exchangers from either teraglycidyl-4,4'-1hiodianiline or cetraglycidyl-4,4'-oxydianiline, combined with polycthylenepolyamine or polycthyleneimine." The radiation stability of these exchangers depends on the moisture content, rather than the basicity of the amine groups. Blectron irradiation of edraglycidyl-4,4'-1hiodianiline:polyethylenepolyaninc 10 1.9 M(iy catused a capacily loss of $30 \%$ when the exchatlger contaned $51.2 \%$ water, whereas the loss was only $19.4 \%$ when the water content was $13.3 \%$.

Kiscleva and coworkers" ${ }^{2}$ studied vinylnyridine-carboxylic acid ampholyte VPK, whose functional group is picolinic acid. The properties of VPK depend on the medium; in alkaline solutions it is a caltion exchanger, whereats in acid solutions the protonated nitrogen hehaves ats an anion exchanger. In neutral and weak acid solutions the predominam intranolecular sall form exhibits a waak swelling that intluences radiolysis.

The principal radiolylic degradalion processes for VPK resin are decarboxylation, rupture of cross links, and oxidation of the resin, "Sodium nitrate protects the VPK macromolecular skeleton against radiation damage, but increases the (i value for decomposing the carboxylic acid from 1.2 to 2 .). 
In another study, Tahakova et al. ${ }^{93}$ used VPK resin loaded with $\mathrm{Sr}(\mathrm{II}), \operatorname{Pr}(\mathrm{III})$, or $\mathrm{UO}_{2}$ (II). The VPK was irradiated in water to doses of 2 (0) $10 \mathrm{MGy}$ with ${ }^{60} \mathrm{Co}$. No metal ions were released into solution during any of these irradiations. Metal complexes appeared to protect the carboxyl groups against decomposition, but increased the rupture of cross-tinks. VPK resin that was completely saturated with metal ions lost no exchange groups in the dose range of 2 to $6 \mathrm{MGy}$. Distribution coefficients for $\mathrm{Sr}(\mathrm{II})$ on irradiated VPK consistently decreased $;{ }^{94}$ however, distribution coefficients for $\operatorname{Pr}$ (III) increased when VPK was irradiated in acetate buffer, but decreased when VPK was irradiated in acetate buffer that also contained sodium nitrate.

The difference in the radiolytic stability of VPK, with or without sorbed $\mathrm{Sr}$ (II), was explained in terms of electron density. In an ampholyte completely loaded with $\mathrm{Sr}$ (II), the electron density is similar to that of benzene because the complex involves not only the carboxylic acid group, but also by a slight withdrawal of electrons from the nitrogen. This shift of electron density in the ampholyte increases the reactivity of the radiolysis products with the less stable cross-links and heterocycles of the VPK, while it suppresses their reactivity with the carboxylic acid group. ${ }^{95} \mathrm{~A}$ separate study with $\mathrm{Ni}$ (II) concluded that the resistance to radiation damage of VPK complexes is in the order $\mathrm{Ni}(\mathrm{II})>\mathrm{UO}_{2}(\mathrm{II})>\operatorname{Pr}(\mathrm{III})>\mathrm{Sr}(\mathrm{II}) .^{96}$

Other interesting multifunctional resins have been prepared and tested with various metal ions. Unfortunately, the radiation stabilities of these resins have not yet been evaluated. Because some of these are especially attractive candidates for radionuclide removal, however, we will discuss a few of them. We strongly encourage the developers of these sorbents or other investigators to determine their radiation stabilities.

Alexandratos and coworkers ${ }^{97}$ synthesized and tested a series of dual-mechanism bifunctional polymers (DMBPs). These DMBPs have a hydrophilic cation-exchange ligand that provides aceess into the polymer network, coupled to another ligand whose reactivity determines the observed specificity. The second ligand provides a recognition mechanism based on reduction, coordination, or precipitation.

Alexandratos et al..$^{98}$ developed a bifunctional phosphinic acid resin specifically for lanthanides and actinides. More recently, Alexandratos et al. synthesized a trifunctional resin known as Diphonix, which has iwo phosphonic acid groups chemically bonded to a single carbon atom, and also has sulfonic acid and carboxylic acid functional groups in its styrenic-based polymer matrix. Although its radiation stability has not yet been determined, this resin has been proposed by its developers as a sorbent for actinides and other radionuclides. ${ }^{99}$

\section{INORGANIC ION EXCHANGERS}

The term "inorganic ion exchanger" was first used by Amphlett, who published the earliest surveys of these materials. ${ }^{100,101}$ Vesley and Pekarek later prepared an exhaustive review of inorganic ion exchangers (with 869 references) for the period 1965-1970. ${ }^{1(12,113}$ Clearfield ${ }^{104}$ and Qureshi and Varshney ${ }^{105}$ also compiled extensive reviews of inorganic exchangers and their applications. Because the composition and degree of crystallinity of these materials greatly affect their sorption properties, their preparation is still being studied. ${ }^{104}$

The number of natural and synthetic materials classified as inorganic ion exchangers has increased greatly during the past four decades. However, because inorganic ion exchange is accompanied by other phenomena such as molecular sieving, physical adsorption, and precipitation, the exact scope of the term "inorganic ion exchanger" is difficult to define.

For much of the past 50 years, inorganic ion exchangers have been proposed for sorbing radionuclides, based on claims of higher mechanical strength and better resistance to heat, radiation, and oxidation than organic polymers. Many of these claims should be viewed with caution, however, hecause they are not always supported by published studies. Another advantage claimed for inorganic exchangers is that some can be directly incorporated into the glass or ceramic materials proposed for long-term storage of radioactive waste. 
Of the many publications about inorganic ion exchangers, relatively few address radiation stability. ${ }^{104}$ Among those that do, many omit the irradiation medium and other important experimental conditions. Because the applications of inorganic ion exchangers in nuclear processing operations have been limited, systematic examination of the effects of radiation on these exchangers also have hecen few. ${ }^{106-112}$

Hooper ${ }^{113}$ discussed the broad classes of inorganic ion exchangers: natural inorganic exchangers, synthetic zeolites, oxides and hydrous oxides, acidic salts of multivalent metals, and cyanoferrates. Hooper et al. ${ }^{114}$ then reviewed the published literature on inorganic exchangers in an excellent 121-page survey with 316 reforences. Based on this review, hydrous titanium oxide, manganese dioxide, titanium and zirconium phosphates, polyantimonic acid, and copper hexacyanoferrate were selected for experimental evaluation.

The effects of gamma radiation on these six sorbents were determined for exposures to 10 MGy. 115 These exchangers generally showed high resistance 10 irradiation to this maximum dose. Manganese dioxide and copper hexacyanoferrate were unaffected by irradiation, whereas polyantimonic acid showed decreasing performance with increasing dose. The performance of zirconium phosphate, titanium phosphate, and titanium oxide decreased up $(0$ a total dose of $2.19 \mathrm{MGy}$, but then appeared to recover at higher doses. Hydrous titanium oxide was the most affected by radiation; moreover, the effects differed for the sorption of different radionuclides, suggesting that the damage mechanism involved a loss of exchange siles resulting from the loss of hydrated water.

Ilydrous titanium oxide was irradiated in its hydrogen and sodium forms by Inoue and Tsuji. ${ }^{116}$ Becatuse they used a low-intensity source of gamma rays, it took 1.5 years to altain the full exposure of 5.2 MGy. The capacity of the hydrogen-form exchanger decreased to about half its initial value in 1.5 years, whether it was irradiated or not, which indicates that the change was due to aging. The capacity of the sodium-form exchanger was unchanged after an identical 1.5 -year irradiation.

Sodium titanate, reported to be selective for strontium, was shown to be highly resistant to gamma radiation. ${ }^{117}$ Essentially no change was observed in its structure or specific surface area after exposure to $10 \mathrm{MGy}$ from ${ }^{60} \mathrm{Co}$. However, Kenna ${ }^{1(18}$ reported a $50 \%$ decrease in the strontium capacity of sodium titanate synthesized al Sandia National Laboratories after a gamma dose of 20 MGy.

Dosch ${ }^{106}$ studied the properties of titanate, niobate, and tantalate salts. The capacity of sodium titanate powder for strontium remained unchanged 10 gamma doses of 0.3 MGy (from ${ }^{60} \mathrm{Co}$ ), but decreased to $50 \%$ of its initial capacity after $20 \mathrm{MGy}$. This capacity loss was attributed to heating during the irradiation. When sodium titanate was incorporated into an organic polymer resin, however, its capacity remained unchanged to $5 \mathrm{MGy}$, but decreased to $30 \%$ of its initial capacity after 20 M(iy. Anion exchange resins loaded with sodium niobate or sodium tantalate exhibited companable sorption properties for strontium, but greater stabilities in acids. These improvements, however, were nof considered sufticient to justify the higher preparation costs of the niobate and tantalate salts.

Dyer and Jamil ${ }^{118}$ lested six inorganic anion exchangers: hydrated zirconium oxide, ferric ferrocyanide, hydrated titanium oxide, hydrated aluminum oxide, lead sulfide, and mercarbide $\left[\left(\mathrm{Clg}_{3} \mathrm{O}\right)_{\mathrm{n}}{ }^{\mathrm{n}+}\left(\mathrm{NO}_{3}\right)_{\mathrm{n}}{ }^{\mathrm{n}}\right]$, as prepared by Weiss and Weiss. ${ }^{119}$ These anion exchangers were irradiated, both wet and dry, to a total dose of 1 MGy. The mercarbide and lead sulfide, when irradiated wel, showed a significant increase in capacity for pertechnetate, whereas the other exchangers lost essentially all of their anion exchange capacity. Dyer et al. ${ }^{120}$ inserted phosphorus(V) into an aluminosilicate zeolite to convert it from a cation exchanger to an anion exchanger; however, the radiation stability of this matcrial was not tested.

Murthy et al. ${ }^{21}$ studied ammonium phosphomolybdate, polyantimonic acid, manganese dioxide, and zireonium antimonate for sorbing cesium, strontium, cerium, and sodium, respectively, in an unspecified acid from 0.21010 M. Measurements before and after gamma irradiations of approximately I MGy showed almost no change in capacitics and only slight changes in distribution coclificients. 
The exchange capacity and clution hehavior of zirconium arsenophosphate ${ }^{122}$ and antimony(V) silicate ${ }^{123}$ are highly resistant to gamma doses of 1 to 3 MGy. Thorium phosphosilicate was only slightly affected by similar irradiations. ${ }^{24}$ The exchange capacities of stannic ferrocyanide, zirconium ferrocyanide, ceric antimonate, titanium antimonate, and ceric tungstate were essentially unchanged by a gamma dose of 10 MGy, although Dowex $50 \mathrm{~W} \times 8$ and Amberlite IR-120 lost $25 \%$ of their capacily during similar irradiations. ${ }^{125}$

When Zr(IV), Sn(IV), and Cr(III) antimonates were exposed to 9 MGy of gamma radiation from a shut-down nuclear reactor, however, their exchange capacities decreased by $36.6 \%, 16.8 \%$, and $31.2 \%$, respectively. ${ }^{109}$ In another study by different investigators, ${ }^{111}$ zirconium phosphate, cerium phosphate, and cerium arsenate were irradiated to 10 MGy in a nuclear reactor core six days after shut-down. No change in the structure of crystalline zirconium phosphate was observed; the structure and other properties of cerium arsenate changed, and the crystal lattice of cerium phosphate was completely destroyed, causing the material (o) become amorphous. The difference between gamma irradiations from ${ }^{61}$ Co and those in a shut-down reactor were altributed to the presence of neutrons in the latter case.

Although neutrons are produced by $(\alpha, n)$ reactions and by spontancous fission even in a shut-down reactor, we question whether the neutron fluence explains the reported differences. Specht et al. ${ }^{77}$ used an operating nuclear reactor as a source of high-intensity gamma radiation and concleded that the fast neutron flux, even in an operating reactor, was negligible for the two reactor positions that he used.

The high selectivity and resistance to radiolytic degradation of certain natural zeolites have made them quite useful for the separation and purification of ${ }^{137} \mathrm{Cs}$ and ${ }^{90} \mathrm{Sr}$ from the millions of gallons of highly radioactive waste stored on the Janford reservation in Washington state. ${ }^{126}$ The development of synthetic zeolites by the Union Carbide Corporation in 1965 and the large-scale manufacture of these materials led to the separation and purification of ${ }^{137} \mathrm{Cs}$ and ${ }^{90} \mathrm{Sr}$ at Hanford, using synthetic \%eolon-90(), clinoptilolite, and Decalso. Synthetic zeolites were also used to immobilize these radionuclides during shipment from Hanford to other parts of the country. ${ }^{127-129}$

Because of inherent difficulties in studying radiation at high dose rates and very high tolal doses, high-dose effects are often extrapolated from lower-dose effects. ${ }^{130}$ \%eolites, being inorganic crystalline materials, were assumed to have a high resistance 10 radiation until 1961, when Iullerton ${ }^{131}$ published the first study of the effects of gamma radiation on clinoptilolite. Although experimental limitations allowed only changes in the hasic crystalline structure 10 be examined, the calcium distribution coefficient decreased by $40 \%$, and sodium distribution also changed significantly.

Few systematic studies of the effects of radiation on zeolife were done before 1979. Alter the Three Mile IslandII (TMI-2) accident on March 28, 1979, numerous studies were performed using commercially available synthetic zeolites. In one such study, Wallace and Bibler ${ }^{132}$ measured the effects of high dose rates and high total doses on Ion Siv ${ }^{T M}$ IE-95, previously called Linde $\Lambda \mathrm{W}-50()$. They claimed that high doses of gamma radiation from ${ }^{60} \mathrm{Co}$ had little effect on the crystal structure of Ion Siv ${ }^{T M}$ IF:-95 and that the distribution coefficient for cesium remained undiminished after total exposures of more than 100 MGy. ${ }^{132}$ This is at odds with systematic studies by Palau, ${ }^{112}$ who reported decreased cesium exchange capacity of Ion Siv ${ }^{\text {TM }}$ IL-95 above total doses of 50 MGy.

Komareni et al ${ }^{133}$ reported that exposure of Ion Siv ${ }^{T M}$ II:-95 and its analogues to high doses of gamma radiation caused a slight increase in the desorption of cesium and sodium from the zeolite and a measurable increase in the leachability of the pollucite. IIowever, a related study by Reilly, et al., ${ }^{134}$ of zeolites recovered from the damaged TM1-2 reactor, reported no evidence of radiation effects on the crystal structure or cesium exchange capacity, even after in situ exposures of 10) MGy. The obvious discrepancies anong these results are attributable to the inherent difficulties of measuring dose and radiation effects at high exposures. 


\section{LIQUID ION EXCHANGERS}

Liquid ion exchange is a special case of solvent extraction, in which the solute is selectively transferred between two immiscible phases. Whereas solvent extraction involves the formation of a neutral species (either a chelate or an ion pair), liquid ion exchange involves only ion pairs. ${ }^{135}$ Liquid anion exchangers are based on high-molecularweight primary, secondary, and tertiary amines, and on quaternary ammonium salts. Liquid cation exchangers include organic compounds with sulfonic, carboxylic, phosphoric, thosphonic, or phosphorous acid groups. ${ }^{136}$

Although the functional groups of some of these cation exchangers may also be considered as chelating agents hecause they coordinate directly to the metal ion, the compounds are commonly classified as liquid ion exchangers. Overlap clearly exists between the liquid ion exchangers and chelating resins. In this review, we use assignments that reflect common practice, as well as whether the exchanger is liquid or solid.

Mechanisms involving liquid ion exchangers generally resemble those of ion exchange resins. IIowever, because liquid ion exchangers require no polymer backbone, they often permit higher concentrations of the functional group, which provide higher capacities. The liquid state of the exchanger also simplifies the design of countercurrent processes.

Moreover, the concentration of functional groups in a liquid exchanger can easily be modified by dilution, which is not feasible with a cross-linked polymer resin. Liquid exchangers also offer greater selectivity, faster exchange kinetics, and more tolerance for suspended solids, than do polymeric exchangers. ${ }^{137}$

Liquid ion exchangers have many proven applications in inorganic analysis. ${ }^{138}$ Because liquid ion exchangers have also been used extensively for nuclear materials processing. the radiation stabilities of many of these compounds have been investigated.

Contarini et al. ${ }^{139}$ studied the extraction of uranium, plutonium, and fission products by Aliquat-336, after exposure to $0.24,0.38$, and $0.57 \mathrm{MGy}$ of ganma radiation. Although low exposures generally decreased the extractions, higher exposures increased the extractions. Although back-extraction of fission products was relatively unaffected by gamma exposure, back-xiraction of plutonium became more difficult as the dose increased. The difference between these results and those of previous studies was attributed to the fact that these researchers irradiated the Aliquot-336 in contact with nitric acid.

Trilaurylaminc, in contact with nitric acid solutions that contained $2 \mathrm{mg}$ of Pu(IV) per ml, was irradiated with ${ }^{61)}\left(\right.$ co to doses of $10 \mathrm{k}$ (iy and $20 \mathrm{k}$ (iy. ${ }^{140}$ The correlation between the quantity of unextracted plutonium in the aqueous phase and the gamma dose was attributed to the formation of strong aqueous-soluble complexes of plutonium with unidentilied radiolysis products.

The TRAMLX process, developed al Oak Ridge National Lahoratory, selectively extracts trivalent actinides from concentrated lithium chloride solution into Alamine-336 in di-isopropylben\%ene. ${ }^{141}$ Neither the extraction and stripping of eurium, nor the physical behavior of the process were impaired by a radiation dose rate of 10 W/liter and a lotal exposure of 100$) \mathrm{W}$-hr/liter. ${ }^{42}$ The only undesirable effect, a loss of hydrochloric acid $((i=1.4)$, was climinated hy adding of 10 volume pereent methanol, after which the solution was stable to a dose rate of $18 \mathrm{~W} /$ liter for 2.5 days.

Tachimori and coworkers studied the radiolysis products of di-(2-ethylhexyl) phosphoric acid (DI:IIPA) and their effects on the extraction of lanthanides ${ }^{143}$ and americium. ${ }^{144}$ In both cases, the initial increase in extraction was attributed to the formation of mono-(2-ethylhexyl)phosphoric acid (MEHPA), and the subsequent decrease to the decomposition of the DEIIPA and MEIIPA (o) phosphoric acid, which forms nonextractable complexes with these trivalent cations. 
Tachimori et al. ${ }^{145}$ also studied the effects of radiation on the separation of lanthanides and transplutonium elements in the TALSPI:AK process. TALSPI:AK preferentially extracts lanthanides into DIEIIPA while the trivalent actinides remain in an aqueous phase of lactic acid and diethylenetriaminepentaacetic acid (D'TPA). Irradiation was found to increase the extraction but to decrease the separation factor, due to radiolytic decomposition of DTPA and formation of MEIPA. The presence of lactate, which suppressed the degradation of DTPA and DEHPA, allowed the system to operate sucesssfully to an absorbed dose up to $200 \mathrm{~W}$-hr/liter. Bond and Leuze 146 also observed MEIIP $\Lambda$ as a radiolysis product of DIEIIP $\Lambda$, but found that this impurity favors the aqueous phase, which provides for "sell-cleaning" of MEUPA in an operating TALSPLAK process.

Tachimori and Nakamura ${ }^{147}$ described general considerations and calculations involved in estimating the absorbed dose for organic extractants being considered for partitioning actinides and fission products from highlevel liquid waste.

The radiolysis of DIIIPA-carbon letrachloride mixtures was studied in the presence and absence of aqueous solutions. ${ }^{148}$ The decomposition of DIBIIP $\Lambda$ was enhanced by the presence of carbon tetrachloride. The yield of hydrogen chloride was increased hy contact with ayueous solution, and increased even more when the two phases were stirred during irradiation. Corrosion of stainless steel by the radiolytic hydrogen chloride was reported.

The effects of gamma radiation on the extraction of $\mathrm{Am}$ (III) by several dialkyphosphoric and monophosphoric acids were studied and compared. $\left.{ }^{149} \mathrm{D}\right) \mathrm{j}($ hexoxyethyl) phosphoric acid (Dholip $\Lambda$ ), the strongest extractant, was the most susceptible to radiation. The radiation stahility of di-(isodecyl) phosphoric acid (DIDPA), which extracts lanthanides more strongly from acid solution than does DEIIPA, is nearly equal to that of DIBHPA. Although DEIIP $\Lambda$ was the weakest $\mathrm{Am}(\mathrm{III})$ extractant, it was the most stable to radiation. MIIIP $\Lambda$ was highly susceptible to radiolytic degradation and was also chemically unstable. Radiolytic degradation of DIDPA, DHolEPA, and MEaIPA was increased by contact with nitric acid during gamma irradiation.

\section{GENLRAL.}

Reliable partitioning agents and technologies are needed to remediate the large quantities of hazardous waste stored in underground tanks at the Hanford Reservation in Washington State. To address this need, a screening study at Los Alamos National Laboratory ${ }^{150}$ measured the distribution of 14 elements on 60 different absorbers from simulant solutions that represented acid-dissolved sludge and alkaline supernate from llanford lligh-Level Waste Tank 102-SY. The selected elements represented fission products (Ce, Cs, Sr, Te, and Y); actinides (U, Pu, and $\mathrm{Am}$ ); and matrix elements ( $\mathrm{r}, \mathrm{Co}, \mathrm{le}, \mathrm{Mn}, \mathrm{Zn}$, and $\mathrm{Zr}$ ). The absorbers included cation and anion exchange resins, inorganic exchangers, composite absorbers, and a series of liquid extractants sorbed on porous heads.

Because the effect of radiation is an important factor when selecting materials to process radioactive waste solutions, the effects of radiation on the most promising absorbers identified by the Los Alamos study ${ }^{150}$ should be measured, when such information is not already available.

\section{ACKNOWILDGMENT}

The preparation of this manuscript was supported in part by the Hanford Progran Office, lEM-36, of the Office of Environmental Restoration and Waste Management, U. S. Department of Energy. 


\section{REFERENCES}

1. Rizzo, I. I.., "Outlook and desires of ion exchange eesin technology development in the nuclear ficld," Fundame'ntals and Applications of Ion Exchange, L iberti, L. and Millar, J. R., Eds., Martinus Nijhoff Publishers, Dordrecht, The Netherlands, 198.5.

2. Egorov, E. V. and Novikov, P. D., Action of Ionizing Radiations on Ion Exchange Materials, Atomizdat, Moscow, 196.5. Isracl Program for Sciontific Translations, Jurusalem, 1967.

3. Ciangwer, T. E., Goldstein, M., and Pillay, K. K. S.. "Radiation effects on ion exchange materials," Report BNL.-50781, Brookhaven National Laboratory. Upton, NY, 1977.

4. Pillay, K. K. S., "A Review of the radiation stahility of ion exchange materials," I, Radiounal. Nucl. Chem. $11) 2(1), 247,1986$.

5. Pillay, K. Y. S., "The effects of ionizing radiations on synthetic organic ion exchangers," J. Radioanal. Nucl. Che'm. 97' 1), 135, 1986.

6. Dhami, I. S., (ropalakrishnan, V., Ramanajam, A., and Dhum wad, R. K., "Studies on the degradation of" anion s' schanger employed for plutonium purification," International Symposium on Radiochemistry and …...', ion Chemistry (Plutonium-50) Years), Bombay, India, lebruary 4-7, 1991, Report INIS-mf-13025, SST-()7.

7. Dessouki, A. M., Zahturan, A. II., Rabie, A. M., and Amer, S. I., "Some investigattions on the radiation stability of a strongly acidic caltion exchange resin," Radiat. P'hy.s. Chem. 33(6), 54.5, 1989.

8. Nlian, ., Dessouki, А., and lil-Assy, N. B., "Ion exchange resins as high-dose radiation dosimeters," Recliat. Phys. Cho'm. 23(4), 441, 19)84.

9. Bartonicek, B., Alabersbergeroval. A., Janovsky, I., Kyscla, J., and Pejsal, R., "Raddiolysis of the AV-17x8 (s anion exchange resin," Redtict. Phy.s. Che'm. 22(3-5), 545, 1985.

10. Tatatkova, S. V., Kiscleva, 1), D., and (hmutov, K. V., "'The change in the ion exchange properties of the VPK ampholyte irradialed in the form of an intramolecular salt," Zh. Fiz. Khim. 56, 361), 1982.

11. Dedgaonkar, V. (i., and Bhavsar, C. M., "Radlation damage to a cation exchanger: self-diffusion kinetics," Radiochem. Radiounal. Lo'tl. 56(4) 217, 1')82.

12. Rannichandran, V., and Misra, B. M., "Studies on the radiation stahility of ion exchange membranes," J. Appl. Polym. S'ci. 32, 5743, 1986.

13. Firsova, L. S., Chuveleva, L. A., Kharitonov, (). V., and Nazatov, P. P., "Investigation of the influence of ionizing raddiation on the chromatographic process of separation of the transplutonium elements," Radiokhimia 27(5) 648, 1985.

14. Swyler, K. J., Dodge, (. J, and Dayal, R., "Assessment of irradiation eflects in radwaste eontaining organic ion-exchange media," Report NURI:(i/CR-3812, U. S. Nuclear Regulatory Commission, Maty 1984.

15. Soo, P. and Milan, L. W., "The impact of I.WR decontaminations of solidification, waste disposal, and associated oceupational exposure," Report NUREG/C'R-34.34, U. S. Nuclear Regulatory Commission, July 199().

16. MeConnell, I. W., Jr., Johnson, D. A., and Sanders, R, D)., "Radialtion degradation in Epicor-II ion exchange resins," Report NIIRI:G/(CR-5.594, U. S. Nuclear Regulatory (ommission, Seplember 199(). 
17. Marsh, S. F., "The effects of ionizing radiation on Reillex ${ }^{T M}$ HPQ, a new macroporous polyvinylpyridine resin, and on four conventional anion exchange resins," Report LA-11912, Los Alamos National Laboratory, Los Alamos, NM, November 1990 .

18. Marsh, S. F., "The effects of in situ alpha-particle irradiations on six strong-base anion exchange resins," Report LA-12055, Los Alanos National Laboratory, Los Alamos, NM, April 1991.

19. Fïsher, S. and Mccarvey, F. X., "Ion exchange mallerials used in nuclear technology," in Ion Exchange' Technology in the Nuclear Fuel Cycle, Report IAlA-TECDOC-365, International Alomic Energy Agency, Vienna, 1986.

20. Pillay, K. K. S., "Radiation effects on ion exchangers used in radioaclive waste management," Report NI:/RWM-8()-3, Pennsylvania Stale Universily, University Park, PA, 1980.

21. Kalkarf, D. R., "Safety evaluation of cation exchange resin," Report BNWL-2391, Batelle Pacific Northwest Laboratory, Richland, WA, 1977.

22. Simon, G. P., "Stability of ion exchangers in ionizing radiation," in Ion Exchange in Pollution Control, Vol. 1, Calınon, C. and Cold, II., Eds., CRC. Press, Boca Raton, Il., Chapt. 5, 1979).

23. IUPAC - "Recommendation on Ion Exchange Nomenclature," Pure Appl. Chem. 29, 619, 1972.

24. Wedermeyer, R. E., "The stability of ion exchange resins to x-rays," Ph. D. Thesis, Vanderbilt University, Nashville, TN, September 1953.

25. Cathers, G. I., "Radiation damage (o) radiochemical processing reagents," Progress in Nuclear Energy Series III, Process Chemistry, Vol.I, Pergammon Press, New York, 1956.

26. Semsushin, A. M., Galitskaya, I. P., and Kuzin, I. A., "Radiation and chemical stability of methacrylic aciddivinylhenzene copolymers," Zh. Prikl. Khim. 44(9), 2035, 1971.

27. Kiseleva, I. D., Chmutov, K. V., Klientovskaya, M. M., and L., V. P., "Radiation stability of KU-4 cation exchange resin," Zh. Fiz. Khim. 41(7), 159), 1967.

28. Ichikawa, T', and Hagiwara, Z., "Iffect of gamma-irradiation on a cation exchanger," J. Nucl. Sci. Tech. 10, 746,1973

29. Tulupov, P. E., Butaev, A. M., Greben, V. P., and Kasperovich, A. I., "IEffect of content of divinylbenzene in KII-2 cation-exchange resins on its resistance lo irradiation in water," Zh. Fiz. Khim. 47(4), 975, 1973.

30). Yee, W. C. and Davis, W., Jr., "Bffects of gamma radiation on cation-exchange resin in a flowing water systcm," Nucl. Sci. ling. 24, 1, 1966.

31. Nabreska, A. and Mazurkiewic\%. B., "liffect of gamma radiation on ion exchange resins IV - Crosslinking and degradation in a Zerolit 225 polystyrenesulfonic cation exchange resin of varying divinylbenzene (DVB) contents," Nukleonika 17(3-4), 169, 1972.

32. Smith, I. L.. and (iroh, II. J., "The effect of gamma radiation on ion exchange resins," Report DP-459, L. I. du Pont de Nemours \& Co., Savanniah River Lahoratory, Aiken, SC, 1961.

33. Kazanjian, A. R. and IIorrel, D. R., "Ratdiation effects on ion exchange resins - I, ( aamma irradiation of Dowex 50W," Report RIP-2140, Dow Chemical Company, Rocky liats Division, (iolden, CO, 1974. 
34. Wiley, R. H. and Devenuto, (i., "Irradialion stability of sulfonated styrene resins crosslinked with various divinylbenzene isomers and mixtures thereof," I. Appl. Polym. Sci. 9, 2001, 1965.

35. Payne, J., "Investigation of mechanism of the $x$-ray degradation of Dowex-.50 ion exchange resin," $M . \wedge$. Thesis, Vanderbill University, Nashville, 'IN, March 1956.

36. Utley, J. W., "The chemical effects of low energy x-radiation on ion exchange resin," Part I of Ph. D. 'Thesis, Vanderbilt laiversity, Nashville, TN, June 1959.

37. Tisher, (i. Il. and Threadgill, W. D., "Terminal report on an applied rescarch program on radiation stability and inorganic radiochemistry," Report T11)-21385, U. S. Atomic lencrgy Commission, Seplember 1964.

38. Wilcy, R. H. and Dyer, R. M., "Analytical and preparative vapor-phase chromatographic separation of divinylbenzene mixlures," I. Polym. Sici. Parl A 2, 3153, 1964.

39. Wiley, R. II. and Venkatachalam, T. K., "Ralles of' sulfonation of polystyrenes crosslinked with pure $p$-, 2:1/m:p)-, and commercial divinylbenzenes," I. Polym. Sici. Part A 3, 1063, 196.5.

40. Swyler, K. J., Dodge, C. IE, and D)atyal, R., "Irradiation effects on the storage and disposal of radioatctive ion exchange media," Report NIIRIE(i/C.R-3383, U. S. Nuclear Regulatory Commission, 1983.

41. Higgins, I. R., "Kadiation damage to organic ion exchange malerials," Report ()RNI,-1325, Oak Ridge National laboratory, ()ak Ridge, TN, lebruary 1953.

42. Askarov, M. A., Dzhalilov, A. T., Nazirova, R. A., and Tsseshko, (i. S., "Radialion slahility of polycondensation ion-exchange resins hased on furfural," Zh. Prikl. Khim. 46(9), $2115,1973$.

43. Shigematsu, T. and ()shio, 'T., "lEffect of cobalt-60) gamma radiation on ion-exchange resin," Bull. Inst. Chem. Rese'arch, Ky'oro Univ, 37, 349, 19.59.

44. Fisher, S. A., "IEffects of gamma radialion on ion exchange resins," Report RM()-2528, U,S. Alomic linergy Commission, 19.54.

4.5. Kiscleva, L. D., (hmulov, K. V., and Krupnova, V. N., "Radialion stability of ion-exchange resins," Zh. Fiz. Khim. 32(11), 2457, 1962.

46. Kiscleva, L. D., ('hmulov, K. V., and Klicntovskaya, V. M., "The radiation slabilily of KU-.5, KI)-6, and E:0-7 polycondensed cation exchange resins," Zh. Fis. Khim. 39(3), 771, 196.5.

47. Kiscleva, E. D., (hmutov, K. V., and Kliculovskaya, V. M., "Action of ionising emission from a stream of aceclerated electrons on polycondensation cation-exchange resins," Zh. Fiz. K'him. 42(11), 2854, 1968.

48. Tulupov, P. L. and Kasperovich, А. I., "liffect of the structure of macromolecules of sulphonic acid cationexchange resins on their stability to radiation," Zh. Fiz. Khim. 42(8), 1978, 1968.

49. Katanjian, A. R. and Horrell, D. R., "Radliation effects on ion exchange resilns - II: AIpha irradialton of Dowex-1," Report Rlip-2534, Dow (hemicial (o., Rocky liats Division, Ciolden, (C), 1975.

50. Pesck, M., "lonizing radiation elfects on various lypes of styrenc-divinylbenzene ion-exchange resins," Jad. Einerg. 14(8), 313,1968.

51. Shetiya, R. S., Unny, V, K. P, and Vartak, D. (i., "Studies on radialion stability of some organic calton \& anion exchange resins," Indian I. Chem. 16A, 24, 1978. 
52. Bauman, L. W., "Radiolysis of ion exclangers used in the purification systems of Savannath River reactors," Report DP.977, E. I. du Pont de Nemours \& Co., Savannah River Laboratory, Aiken, SC., July 1965.

53. Basinski, A., Nabreska, A., and Tempezyk, M., "laffect of gaunma radiation on ion exchange resins. I Irradiation damage of functional groups in the strong base anion-exchange resin Zerolit FF-IP." Nukleonika $14(5), 509,1969)$.

54. Nabreska, A., Basinski, A., and Litowska, M., "Effect of gamma radialion on ion exchange resins II Investigation of the effect of gamma radiation on \%erolit lil-IP by the IR method," Nukleonika 15(2), 177 , 1970.

55. Lilowska, M. and Basinski, $\Lambda$., "liffect of gamma radiation on ion exchange resins $V$ - Kinetics of radiation damage of strongly alkaline function groups in anion exchange resin \%erolit lil:-IP," Nukleonika 18(5), 195, 1973.

56. J.ilowska, M., Nabreska, $\Lambda$., and ()strowska, J., "liffects of gauma radiation on ion exchange resins VI - The kinclics and mechanism of radiation-induced decomposition of functional groups in an IMAC \$5-40 anion exchange resin," Nukleonika 19(1), 21, 1974.

57. Hall, ( $i, R$. and Streal, M., "Radialion-induced decomposition of ion-exchange resins: I. Anion-exchange resins," I. Chem. Soce B, 5205, 196.3.

58. Ahmed, M. T., Clay, P. (i., and Hall, (i. R., "Raddation-induced decomposition of ion-exchange resins: Part 11 - The Mechanism of the deamnination of anion exchange resins," I. Chem. Soc', 1155, 1966.

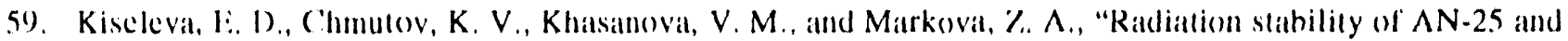
AN-2.5A anionlexchange resins," Zh. Fis. Khim. 45(4), 897, 1971.

60). Kiscleva, L. D., Khasanova, V. M., and ('hmutov, K. V., "The radiation stability of AVKh-8P' and AVI-8P" quinoline and isouminoline anion exchange resins," Zh. Fis. Khim. 45(5), 1192, 1971.

61. Khasanova, V, M., Kiscleva, L. D)., and (hmutov, K. V., " $\wedge$ n infrared spectroscopic study of the changes in the structure of $A \vee K h-8$ and $A$ VI-8P' anion exchange resins under the influence of ionising radiation," $Z h$. Fiz. K'him. 45(5), 1277, 1971.

62. Kiscleva, E. D), (hmutov, K. V., and Kuligina, N. V., "The mechanism of the effect of ionising radiation on AV-17 anion-exchange resin," Zh. Fiz. Khim. 44(2), 472, 197().

6.3. Kiscleva, E, I), Chmutov, K. V., and Fïlatova, N. V., "Ratdiation stability of ion-exchange resins: III. Action of an ionising flux of aceelerated clectrons on anion-exchange resins," Zh. Fiz. Khim. 36(1), 246.5, 1962.

64. Kiseleva, L. 1)., Tabakova, S. V., and ('hmutov, K. V., "Kincties of the sorption of the hexanitratoplutonate anion on irradiated AN-24 anion-exchange resin," Zh. Fiz. Khim. 50(9), 237.5, 1976.

6.5. Kiscleva, E. D., Tabakova, S. V., and (hmutov, K. V., "Kinclies of the Sorption of the hexanitratoplutonale anion on AN-24 anion-exchange resin irradialed in nitric acid," Zh. Fiz. Khim. 50(9), 2377, 1976.

66. Kazanjian, A. R. and Stevens, J. R., "Radiation effects on MS(-1, Amberlite 252, and Duslite ( -264 ion exchange resins," Report RFP-3541, Rockwell International Rocky liats Plant, (iolden, (C), 1983.

67. Kazanjian, A. R. and Killion, M. L., "Radiation effects on Amberlite IRA-9)38 and Bio-rad A(i-MP-50) ion exchange resins," Report RlP-3167, Rockwell International Rocky lifats Plant, (iolden, (c), 1982. 
68. Ciribanova, I. N., Khol'kina, I. D., Polovinkin, Yu. N., and Nikolaev, $\Lambda$. V., "Radliation, chemical, and mechanical stability or porous organophosphorus ciltion exchangers," Zh. Fiz. Khim. 44(7), 17.52, 1970).

69). Calmon, (... "lixplosion hazards of using nitric acid in ion-exchange equipment," Chem. ling. November 17, 196()$, 271$.

70). Miles, F. W., "Ion-exchange-resin system failures in processing actinides," Nucl. Safefly" 9(5), 394, 1968.

71. Ryan, J. L., "Procecdings of the US-IIK Technical lixchange Meding, ( )ak Ridge National Laboralory, April 25-27, 1960," Report 'I'1)-7607, I, s. Atomic linergy ('ommission, 1961, 2.

72. Calleri, G., (ieoffroy, A., Franssen, l., and I)emonic, M., "Study of the kinelic's of loadling Pu(IV) on Permutit SK resin from 7.2 M nitric acid," laurochemic Technical Reporl No. 120), (NI-12345), 1961.

73. Marston, (.. R., Reilly Industries, Inc., Indianapolis, IN, personal communication, November 1988.

74. Zatinutdinov, S. S.. Dzhalilov, A. T'., and Askarov, M. A., "Study of the radiation resistance of anionexchange resins made of epichlorohydrin with vinylpyridines," Zh. Prikl. Khim. 55(8), 1862, 19)82.

75. Marsh, S. R., "Reillex ${ }^{T M}$ HP(): $\wedge$ new macroporous polyvinylpyridlue resin for separating plutonium using nitrate anion exchange," Solv. E.atr. Ion Eit'h. 7(.5), 9)8, lo89).

76. Kazanjian, A. J. and Ilorrell, 1). R., "Radliallon effects on ion-exchange resins III: Alpha irradiation of Dowex 50W," Report DP-RIP-2298, Dow (Chemical (o., Rocky lilits Division, (iolden, (C), Junc 1975.

77. Specht, S., Schutz, B. ()., and Borm, II.-1., "I)evelopment of a high-pressure ion-exchange system for rapid preparative separations of Iransuranium clements,".I. Radiounal. Chem. 21, 167, 1974.

78. Partumonova, V. I., Vysokoostrovskaya, N. B., Nikolace, V. M., Osipos, S. V., and Irolov, V. I., "Influence of internal alpha-irradiation on the characteristics of the anion-exchange resin $\Lambda \mathrm{V}-23 \mathrm{M}$," Radiok-himia 12(1), 127,1970 .

79. Alirens, R. W., "Alphat-particle radiolysis on anion exchange resins," Report DP-6.54, li. I. du Pont de Nemours \& (o., Savannah River Liboratory, Aiken, s(', November l961.

8(). Almed, M. T., "Decomposition of anion exchange resins by alphat and gamma radiations," Ph.l). thesis, Imperial college of Science and technology, University of London, Seplember 196.5, 8.3.

81. Marsh, $\$$, l., "The effects of extermal gammat radiation and of in sim alpha particles on five strong-base

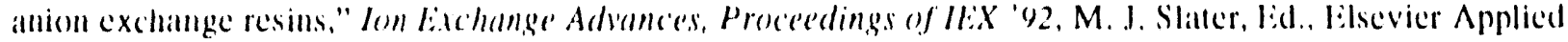
Science, london and New York, 1992, 35x.

82. Myasocdova V. (i. and Savvin, S. B., "New chelating sorbents and their use in antalytical chemistry," Zh. Anc1. Khim. 37. 49\%, 1982.

83. Millar, J. R., Petruzelli, D), and Tiravanti, (i., "Some problems in the use of chelating resins for convironmen-

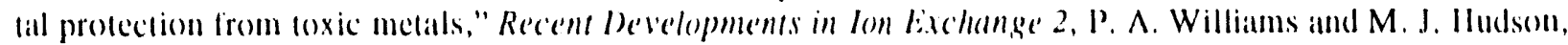
Eds., Basevier Applied Scicince, I, ondon and New York, 199), 3.37.

84. Sengupta, A. K. and \%hu, T., "( 'helating polymers wilh nitrogen donor anoms: some unique properties and related application potentials," New developments in lon lixchange: Malterials, landiunentals, and Applical-

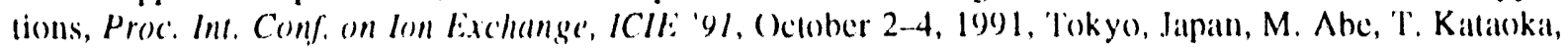
and 'T. Suzuki, lids., Elsevier, New York, 19)2, 561. 
8.5. (ireen, B. R. and llancock, R. D., "Recent advances in the development of resins for use in hydrometallurgy," Hydrometall. 81, Proc. Soc. Chem. Ind. Symm., 1981, E6: 1-13.

86. Eecles, II, and Greenwood, II., "(helate ion-exchangers: the past and future applicaltions, a user's view," Solv. Extr. lon Exch, 10(4), 713, 1992.

87. Murty, G. S., "Iiffect of gamma radiation on carboxylic acid ion-exchange resins," Proce Nucl. Chem. Radiochem. Symp., 1981, 708.

88. Pfrepper, (i., Mai, Il., Ilerrmann, M., and l.angguth, HI., "The resistance of ion exchangers to nitric acid and radiation: III. Investigations of the resistance of the Wof MC 50) type chelating ion exchanger to gamma radiation in the air-dry state and in nitric acid," Readiochim. Acta 28, 177, 1981.

89. Tulupov, P. L., Paslikov, A. B., Slabkaya, 1. D., I.yustgarten, I. I., Zhuravleva, I. I., and Sharkova, I. A., "Radiechemical synthesis and properties of a cation exchanger based on bis-2,2"-chlorocthyl ester of vinylphosophonic acid and divinylhenzene," Zh. Prikl. Khim. 44(9), 2(29), 1971.

90). Nikolacv, A. V., (irihanova, I. N., Yakovleva, N. I., and Khol'kina, 1. D., "Raddiation stability of complexforming organophosphorus resins," Zh. Fit. Khim. 40, 848, 1966.

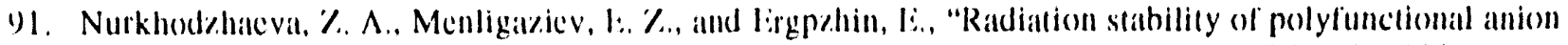

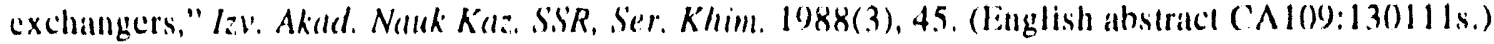

92. Kiscleval, E. D., Tabakovil, S. V., and (hmulov, K. V., "Structure of VP-K amphoteric ion-exchange resin investigalled by intrared spectroseony." Zh. Fiz. Khim. 48(5), 1106, 19974.

93. Tabakeva, S. V., Kiseleva, I. 1)., and ('hmutev, K. V., "The change in the ion-exchange properties of the VPK ampholyte on irradiation in the form of complexes," Zh. Fiz. Khim. 56, 372, 1982.

94. Tahakova, S. V., Kiscleva, E. D), and (homulov, K. V., "The selectivily of the VPK ampholyte irradiated in the form of an intramolecular sall," Zh. Fiz. Khim. 56, 217, 1982.

95. Tabakova, S. V. and Kiscleva, L. D)., "(hanges in the Ion lixchange Properties of the vinylpyridine carboxylic acid ampholyte irradialed in the metal complex form; II. Ion exchatnge properties of vinylpyridine carboxylic acid irradiated as strontium complexes," Zh. Fiz. Khim. 60), 31011, 1986.

96. Tabakova, S. V. and Kiscleva, I. D., "(hatnges in the Ion Exchange Properties of the vinylnyridine carboxylic acid ampholyte irradiated in the metal complex form: III. Irradianton of vinylpyridine carboxylic acid as nickel complexes." Zh. Fi.. Khim. 61), 31144, 1986.

97. Akxandrates, S. 1)., (rick, D). W., and Quillen, D. R., "I)evelopment of bifunctional polymers for metal ion separations: Ionic recognition with polymer-supported reagents," Ind. Ing. Chem. Res. 30, 772, 1991.

98. Alexandrat(os, S. D., Quillen, D. R., and Mel)owell, W. J., "Bifunctional phosphinic acid resins for the complexation of lamlhanides and actinides," S'pe. Sci. Téchnol. 22(2\&3), 983, 1987.

99. Horwitz, L. P., (iatrone, R. C., (Chiarizia, R., Nash, K. L., Alexandratos, S. D., Trochimezuk, A. W., and ('rick, D. W., "Diphonix: a new chelate ion exchange resin," oral presentation only, IEX '92 Int. Conf. on lon Exchange Adverances, Churchill College, Cambridge Universily, England, July 12-17, 1992.

100). Amphlet1, C. B., "Synthetic inorganic ion exchangers and their applications in atomic energy," Proceedings of the Second International Conference on the Peaceful Uses of Atomic Energy, Geneva 1959, Vol. 7, United Nalions, New York, NY, 195\%, P/271. 
101. Amphlell, (․ B., Inorganic Ion Exchangers, Llsevier Publishing Compally, New York, 1964.

102. Vesley, V. and Pekarck, V., "Symthedic inorganic ion exchangers - l," Tulanta 19, 219 (1972),

10.3. Pekatrck, V. and Vesley, V., "Synthetic inorganic ion exchangers - II," Talanta 19, 1245 (1972).

104. Clearficld, A., Ld., Inorganic Ion Exchange Materials, C.RC Press, Inc., Boca Ratom, lo, 1982.

105. Qureshi, M. and Varshney, K. (i., lids., Inorganic lon Exchangers in Chemical Analysis, CRC Press, Boca Rill(I), IIL, I)1.

106. Dosch, R. ( $i$. ., "limal report on the applicition of titatnates, nioballes and tantalates to neutralized defense waste decontamination - materials properties, physical forms, and regeneration techniques," Report SAND). $8(1)-1212$, Sandia National Laboratories, Albuguerque, NM, 1981.

107. Lrmatov, S. L., "liflects of gamma-ray exposure on the adsorption capacity of KSM-6 silica gel," Lav. Acad. Nauk. Kazakh. SSR, Phys. and Math. Sur. No.4, 48, 1967.

108. Kenna, B. T., "Radiation stability of" sodlum titunate ion exchange materials," Report SAND)-79)-(0199, Sandia Naltional Iaboratories, Albuquerque, NM, 1980).

109. Mathew, J., Tandon, S. N., and (iill, J. S., "IEffects of gamma radiation on exchange characteristics of some antimonales," Redioc'he'm. Roddiocenal. Le'll. 30)(5-6), 381, 1977.

110. Singh, N. J., Tandon, S. N., and (iill, J. S., "Resistance of zirconium arsenophosphate ion exchanger against gaumma radiation," Raddeche'm. Radiounel. Le't1, 41(1), 79, 19979.

111. \%sinka, I., Szirles, L., Mink, I., and Kalman, A., "Effects of gatmma ratdiation on various synthetic inorganic ion exchangers," J. Inorg. Nucl. Chem. 36, 1147, 1974.

112. Paalatu, (i. L., "A study of gamma radiation effects on \%colite and steds used in ion exchange systems," Master's Thesis in Nuclear linginecring, Pennsylvania State Universily, Iniversity Patrk, PA, 1986.

113. Hooper, l:. W., "The application of inorganic ion exchangers to the treatment of medium active effluents,"

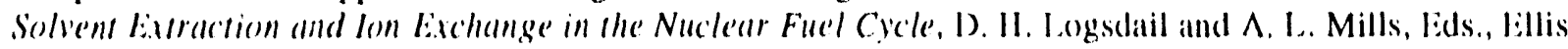
Horword limiled, ( 'hichester, Ingland, 1985. 145.

114. Hooper, E. W., Phillips, B. A., Dagnall, S. P., and Monckton, N. P., "An assessment of the application of" inorganic ion exchangers to the treatment of intermediate level wastes," Report AIERL-R II ()88, AIERE, Harwell laboratory, lingland, 1984.

115. Phillips, B. A., Hooper, L. W., and Monckion, M. P., "Study of inorganic exchangers in the treatment of

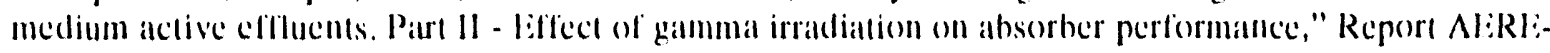
(i.3857, AERL, Harwell Laboratory, Lagland, 19866.

116. Inoue, Y, and T'suji, M., "Situdies of the hydrous tilinium oxide ion exchanger. IV; The effect of radiation and heall treallmene," Bull. Chem. Soce. Japan 51(3), 794, 1978.

117. I.chlo, I. and Mietlinen, J. K., "Sodium titanate - a highly selective inorganic ion exchanger for strontium,"

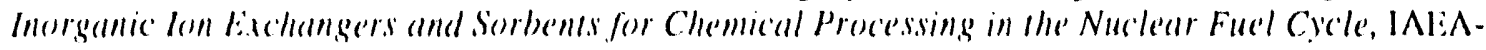

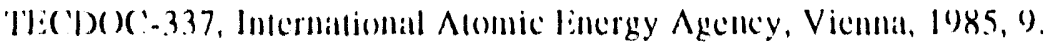


118. Dyer, $\Lambda$. and Jamil, M., "Inorganic anion exchangers for the traument of radioactive wastes," Ion Exchenge for Industry, Streat, M., Ld., Lillis Ilorwood Limited, 1988, 495.

119. Weiss, А. and Weiss, A. Z., "Mercarbide as an anion exchangur," Z. Anorg. Allgem. Chem. 282, 324, 1955.

120. Dyer, A., Malik, S. A., Araya, A., McConville, T. J., "New anion exchangers of the zeolitic type," Recent Developments in lon Exchange, Williams, P. A. and Iludson, M. J., Eds., Elscvicr Applied Science, London and New York, 1988, 257.

121. Murthy, T., S., Balisubrananian, K. R., Ralo, K. R., and Narasumha, K. L., "Radiation stability of inorganic exchangers used for lission product separation," Proc. Nucl. Chem. Radiochem. Symp., 1980, Bombay, India, $3(1)$.

122. Varshney, K. G., Varshney, K., and Agrawal, S., "Ion exchange behavior and selectivity behavior of thermally treated and gamma-irradialed phases of zirconium arsenophosphate cation exchanger: Separation of Al(111) from some silicale rocks," Sep. Sci Technol. 18, 905, 1983.

12.3. Varshney, K. G., Sharma, U., Rani, S., and Prenadas, A., "Cation exchange sludy on crystalline and thermally stable phase of antimony(V) silicate: Effect of irradiation on its ion exchange hehavior and separation of Cl(II) from Zn(II) and $\mathrm{Mn}$ (II), and of $\mathrm{Mg}$ (II) from Ba(II), Ca(II) and Sr(II)," Sep. Sci. Technol. 17, 1527, $1982-1983$.

124. Varshney, K. Ci., Sharma, U., and Rani, S., "Synthesis and analytical applications of thorium(IV) phosphosilicate, a new mercury selective cation exchanger: Effect of irradiation on its ion exchange behavior," J. Indian Che'm. Soc', 61, 220, 1984.

125. Gill, J. S. and Tandon, S. N., "Investigation of the resistance of some inorganic ion exchangers against gamma radiation," Radiochem. Radioanal. Lett. 14, 379, 197.3.

126. Mereer, B. W. and Ames, L. L.., "Zeolite ion exchange in radioactive and municipal waste water treatment," Nanural Zeolites - Occurrences, Properties, and Uses, Sand, L. B. and Mumpton, F. A., Eds., Pergamon Press, New York, NY, 1978, 415.

127. Sherman, J. D., Senior Development Associate, Union Carbide Corporation, personal communication, November 24, 1980.

128. Schultz, W. W., Chief Scientist, Rockwell Hanford Operations, personal communication, July 22, 1980.

129. Ryan, J. L., Senior Research Scientist, Battelle Pacific Northwest Laboratories, personal communication, October 7, 1980 .

130. DOE 'Task Force, "Evaluation of" increased cesium loading on submerged demineralizer system (SDS) Zeolite beds," Report DOE/NE-(0)12, U. S. Department of Energy, 1961.

131. Fullerton, R., "The effects of gamma radiation on clinoptilolite," Report HW-69256, Ilanford Atomic Products Operation, Richland, WA, April 1961.

132. Wallace, R. M. and Bibler, N. E., E. I. du Pont de Nemours \& Co., Savannah River Laboratory, Aiken, SC, Personal communication, February 20, 1981.

133. Komarneni, S., Palau, G. L., and Pillay, K. K. S., "Radiation effects on a zeolite ion exchanger and a pollucite," Nucl. Chem. Waste Manage. 4, 335, 1983. 
134. Reilly, J. K., Grant, P. J., Quinn, (i. J., Runion, 'I', C.., and Ilofstetter, K. J., "Radliation edfects on resins and zeolites at Three Mile Island Unit II," Ifffects of radiattion on materials: Twelfh Int. Symp., Vol. II, AS'TM

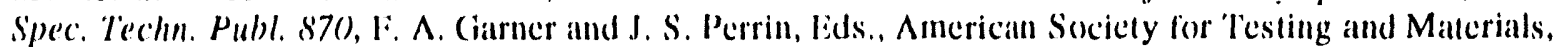
$198.5,1238$.

135. Calmon, C., "Liquid ion exchangers," Ion Exchange for Pollution Control, Vol. II, Calmon, C. and Ciold, II., Eds., CRC Press, Boca Ralkn, Fil, 1980), 161.

136. Wallon, 11. 1. and Rocklin, R. D., Ion Exchange in Analytical Chemistry, CRC Press, Boca Ratom, lil, lox!! 2.5 .

137. Rieman, W., III and Walton, II. L., Ion Exchange in Analytical Chemistry, Pergamon Press, New York, NY, 1970), 228 .

138. Cireen, 11., "Uses of liquid ion-exchangers in inorganic analysis," Talanta 20, 139, 1973.

139. Contarini, M., Pasquinelli, P., and Rigali, L., "The effect of gamma irradiation on extraction properties of a quaternary ammonium extractant," Readiechim. Actu 22(1-2), 88, 1975.

140. Bhallacharya, P. K. and Vecraraghaven, R., "Effect of radiation on the extatction of Pu(IV) by triliarylaminc," Radiochem. Redioanal. Lett. 17(5-6), 297, 1974.

141. Baybarz, R. D., Weaver, B. S., and Kinser, II. B., "Isolation of transplutenium elements by tertiary amine extraction," Nucl. Sci. ling. 17, 457, 1963.

142. Burch, W. D., Transuranium Quarterly Progress Report, November 30, 1963, Report ORNL,-3597, Oak Ridge National Lahoratory, Oak Ridge, 'TN, 1964, 8.

143. Tachimori, S., Krooss, B., and Nakamura, H., "Effect of radiolysis products of di-(2-ethylhexyl)phosphoric acid upon the extraction of lanthanides," I. Radiounal. Chem. 43, 53, 1978.

144. Tachimori, S., "Radiation effects on the extraction of americium(III) with di-(2-ethylhexyl)phosphoric acid," J. Radiounal. Chem. 50(1-2), 133, 1979.

145. Tachimori, S. and Nakamura, H., "Radiation effects on the separation of lanthanides and transplutonides by the TALSPEAK-type extraction," I. Radioanal. Chem. 52(2), 343, 1979.

146. Bond, W. D. and I cuze, R. L., "Removal of americium and curium from high-level waste," Actinide Separations, ACS Symp. Ser. 117, J. D. Navratil and W. W. Schulz, Eds., American Chemical Socicly, Washington, D. (.., $1980,441$.

147. Tachimori, S. and Nakamura, II., "Radiation damage of organic extractants in partitioning of high-level liquid waste (II)." I. Nucl. S'ici. Téchnol. 16(5), 36.3, 1979).

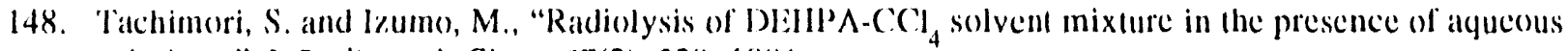
solutions,".J. Radionanal. Chem. 67(2), 329, 1981.

149. Tachimori, S., Nakanura, II, and Sallo, $\Lambda .$, " $\Lambda$ study of radiation effects on the extraction of americium(III) with acidic organophosphales," J. Radioanal. Chem. 50(1-2), 143, 1979).

150. Marsh, S. F., Svitra, \%. V., and Bowen, S. M., "I)istributions of 14 elements on 60) selected absorbers from (Wo) simulant solutions (acid-dissolved sludge and alkaline supernate) for Ilanford IILW Tank 102-SY." Report L.A-120.54, L.os Alamos National Laboratory, Los Nlamos, NM, October 1993. 

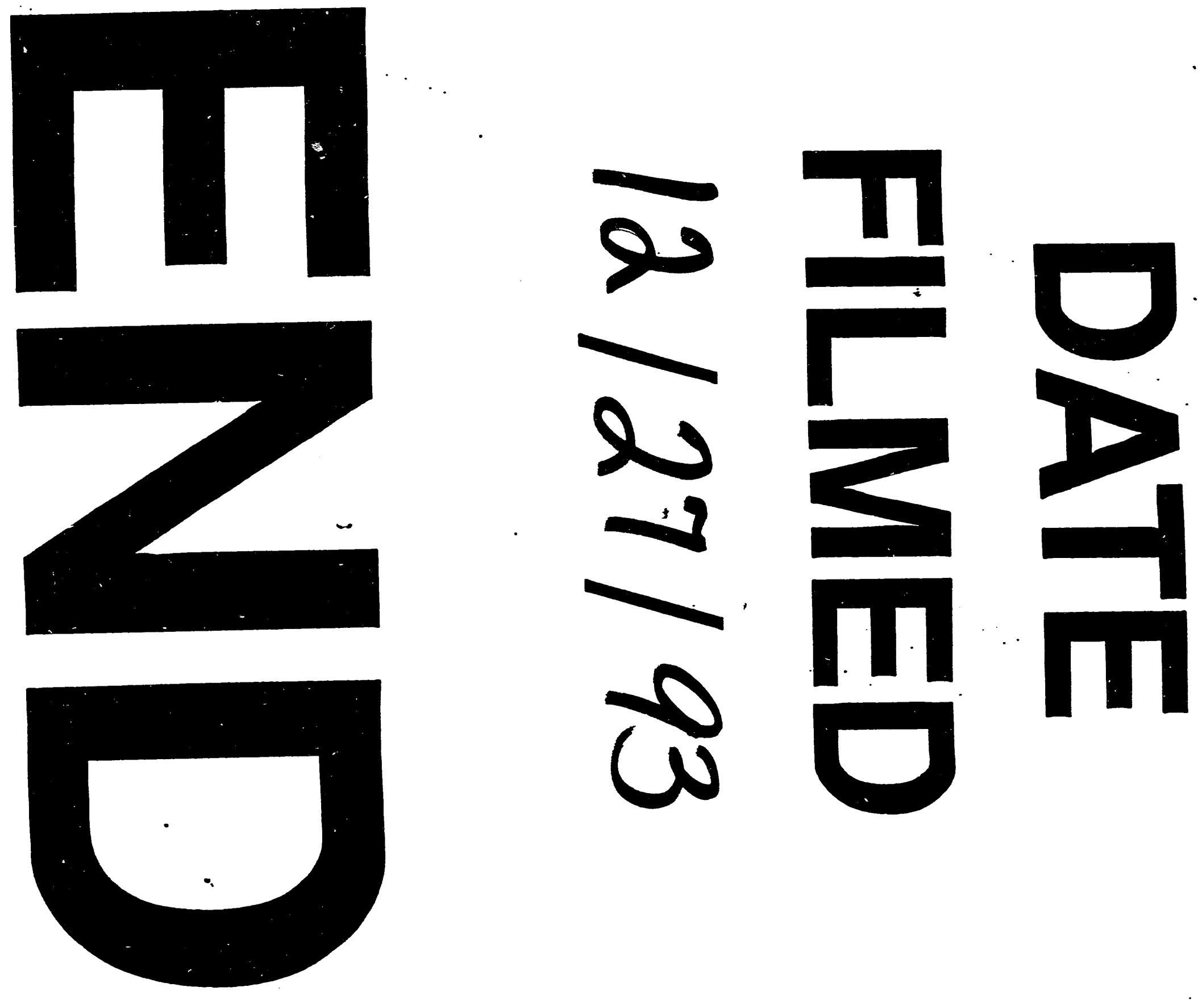
• 